\title{
A Myeloma Paraprotein with Specificity for Platelet Glycoprotein Illa in a Patient with a Fatal Bleeding Disorder
}

\author{
Giovanni DiMinno, Francesco Coraggio, Anna M. Cerbone, Anna M. Capitanio, Ciro Manzo, Marcello Spina, \\ Paolo Scarpato, Guido M. R. Dattoli, Pier Luigi Mattioli, and Mario Mancini \\ Istituto di Medicina Interna e Malattie Dismetaboliche II Policlinico, e Cattedra di Medicina d'Urgenza I Policlinico, \\ Università degli Studi di Napoli; Centro per l'Emofilia e la Trombosi, Università di Milano \\ e Fondazione Pascale per lo Studio e la Cura dei Tumori, Napoli, Italy
}

\begin{abstract}
Impaired platelet aggregation, normal shape change, and agglutination and normal ATP secretion and thromboxane synthesis in response to high concentrations of thrombin or arachidonic acid were found in a patient with multiple myeloma and hem-

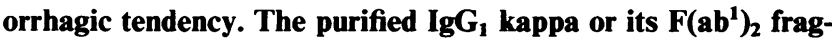
ments induced similar changes when added in vitro to plateletrich plasma from normal subjects. In addition, the paraprotein inhibited adhesion to glass microbeads, fibrin clot retraction, and binding of radiolabeled fibrinogen or von Willebrand factor to platelets exposed to thrombin or arachidonic acid without affecting intraplatelet levels of CAMP. The radiolabeled paraprotein bound to an average of 35,000 sites on normal platelets but it bound to $<2,000$ sites on the platelets from a patient with Glanzmann's thrombasthenia. Immunoprecipitation studies showed that the platelet antigen identified by the paraprotein was the glycoprotein IIIa. Furthermore, binding of radiolabeled prostaglandin $E_{1}\left(P G E_{1}\right)$ to resting platelets as well as binding of von Willebrand factor to platelets stimulated with ristocetin were entirely normal in the presence of patient's inhibitor. These studies indicate that bleeding occurring in dysproteinemia may be the result of a specific interaction of monoclonal paraproteins with platelets. In addition, our data support the concept that the interaction of fibrinogen and/or von Willebrand factor with the platelet glycoprotein IIb-IIIa complex is essential for effective hemostasis.
\end{abstract}

\section{Introduction}

Patients with dysproteinemia and hemorrhagic tendency often have hemostatic abnormalities and circulating monoclonal paraproteins (1). Most of these paraproteins have been identified as immunoglobulin inhibitors of phospholipids (2) or major components of the coagulation cascade (3-7); however, inhibitors of platelet function have also been reported (8-11). Platelet abnormalities in dysproteinemia include impaired platelet aggre-

Portions of this work were presented at the 84th meeting of the Italian Society of Internal Medicine, Milano, Italy, 5-8 October 1983; and have been published in abstract form, 1984. Atti LXXXIV Congresso della Società Italiene Medicina Interna. 93.

Address reprint requests to Dr. DiMinno, Clinica Medica II, Nuovo Policlinico, Via S, Pansini, 5, 80131, Napoli, Italy.

Received for publication 22 April 1985 and in revised form August 201985 .

J. Clin. Invest.

(c) The American Society for Clinical Investigation, Inc.

$0021-9738 / 86 / 01 / 0157 / 08 \quad \$ 1.00$

Volume 77, January 1986, 157-164 gation and adhesiveness and reduced Factor III availability and are thought to occur as a consequence of nonspecific adherence of the inhibitor to the platelet surface $(1,8-11)$. We have studied a patient with multiple myeloma, marked hemorrhagic tendency, and in vitro platelet abnormalities, whose monoclonal paraprotein induces a thrombasthenic-like state in normal platelets. We report here that inhibition of platelet function by this antibody is the result of a specific immunologic reaction with the glycoprotein IIIa (GPIIIa) ${ }^{1}$.

\section{Methods}

Preswollen microgranular DEAE cellulose was from Whatman, Inc., Clifton, NJ. Firefly luciferase and luciferin (Chronolume 395) were purchased from Chrono-Log Corp., Havertown, PA; disodium EDTA and 2-dithiothreitol (DTT) were obtained from Fisher Scientific Co., Pittsburgh, PA. EDTA was prepared as a 100 -mM stock solution in distilled water (pH adjusted to 7.4 and 8.7 with $\mathrm{NaOH}$ ). Pepsin $(2,500 \mathrm{U} / \mathrm{mg}$ ) was from Worthington Biochemical, Freehold, NJ; Nonidet P40 was obtained from Particle Data Inc., Elmhurst, IL and Triton X-100 was obtained from Amersham Corp., Arlington Heights, IL. Acrylamide, $N$ $N$-methylene-bis-acrylamide, Coomassie Brilliant Blue R250, and molecular weight standards were from Bio-Rad Laboratories, Richmond, CA; bovine serum albumin (Pentex fraction V) was from Miles Laboratories, Inc., Elkhart, IN. Hirudin, phenylmethylsulphonyl fluoride (PMSF), ADP, ATP, sodium dodecyl sulfate (SDS), Hepes, lactoperoxidase (70-100 U/mg protein) agar, and prostaglandin $E_{1}\left(P E_{1}\right)$ were from Sigma Chemical Co., St. Louis, MO. Agar and SDS were dissolved in distilled water immediately before each series of experiments; ADP, ATP, and hirudin were dissolved in distilled water and stored in small aliquots at $-20^{\circ} \mathrm{C} ; \mathrm{PGE}_{1}$ was dissolved in ethyl alcohol and stored at $-20^{\circ} \mathrm{C}$. Thrombin (Parke Davis and Co., Detroit, MI) was dissolved in distilled water and stored in small aliquots at $-70^{\circ} \mathrm{C}$. Protein A-Sepharose CL 4B and cyanogen bromide-activated Sepharose were from Pharmacia Fine Chemicals, Piscataway, NJ. Arachidonic acid (AA) and calcium ionophore A23187 were kindly provided by Dr. Renato Saggiorato (Menarini Diagnostici Firenze, Italy). Protosol, $\left[{ }^{14} \mathrm{C}\right]$ inulin, carrier-free ${ }^{125} \mathrm{I}$-sodium iodide, and $\left.{ }^{3} \mathrm{H}\right] \mathrm{PGE}_{1}$ were from New England Nuclear, Boston, MA. Istangel scintillation fluid and Tri-Carb 2660 betacounter were from Packard Instrument Co., Inc., Downers Grove, IL. Antisera anti-human IG/L chains of kappa and lambda type were from Behringwerke AG, Marburg, West Germany; murine monoclonal IgG to human $\mathrm{IgG}_{1}, \mathrm{IgG}_{3}$, and $\mathrm{IgG}_{4}$ were from Thecno-Genectics, S. Mauro Torinese, Italy, and alkaline phosphatase conjugated goat $F\left(a b^{1}\right)_{2}$ fragments antimouse IgG were from Cappel Scientific Division, Malvern, PA. Highly specific antibodies to thromboxane $\mathrm{B}_{2}\left(\mathrm{TxB}_{2}\right)$ were from Seragen Inc., Boston, MA. Silicone oils (methyl-silicone 1.0 DC 200 and Hi-phenyl

1. Abbreviations used in this paper: AA, arachidonic acid; cAMP, cyclic AMP; DTT, 2-dithiothreitol; GPIIIa, glycoprotein IIIa; GPIIb-IIIa, glycoprotein IIb-IIla complex; $M_{\mathrm{r}}$, relative molecular weight; PFP, plateletfree plasma; $\mathrm{PGE}_{1}$, prostaglandin $\mathrm{E}_{1}$; PMSF, phenylmethylsulfonyl fluoride; PRP, platelet-rich plasma; $\mathrm{TxB}_{2}$, thromboxane $\mathrm{B}_{2}$; vWF, von Willebrand factor. 
silicone 125 DC 550) were from W. F. Nye, Specialty Lubricants, New Bedford, MA. Mixtures of DC 200 and DC 550 were prepared as previously described (12). Kits for the radioimmunoassay of cyclic AMP (cAMP) were from Beckton-Dickinson \& Co., Oxnard, CA. Von Willebrand factor (VWF) purified, characterized, and labeled according to Ruggeri et al. (13) was kindly provided by Dr. A. Federici, Milano, Italy. Formaldehyde-fixed platelets; fibrinogen purification, characterization and labeling; $\mathrm{TxB}_{2}$ measurements; intraplatelet cAMP; platelet secretion of nucleotides; platelet fibrin clot retraction and binding to platelets of radiolabelled fibrinogen, $\mathrm{PGE}_{1}$, and $\mathrm{vWF}$ were handled as recently reported (12). For preparation of platelet-rich plasma (PRP), platelet-free plasma (PFP), and suspensions of washed platelets, nine volumes of blood were collected from the antecubital vein via a 19-gauge scalp vein needle into a plastic tube containing 1 vol of 3.8\% trisodium citrate. PRP was obtained by centrifugation of the blood at $200 \mathrm{~g}$ for $15 \mathrm{~min}$ at room temperature and PFP was obtained by centrifuging fresh PRP in an Eppendorf centrifuge (Beckman Analytical, Milano, Italy) at 12,000 g for $5 \mathrm{~min}$. For preparation of platelet suspensions, aliquots of PRP were cooled on ice for $30 \mathrm{~min}$ and EDTA was added to a final concentration of $5.6 \mathrm{mM}$. After centrifugation at $2,000 \mathrm{~g}$ for $6 \mathrm{~min}$ at $4^{\circ} \mathrm{C}$ in a centrifuge (J-6B; Beckman Instruments, Inc.), the platelets were resuspended in a volume of buffer $(0.14 \mathrm{M} \mathrm{NaCl}, 20 \mathrm{mM}$ Tris, $5 \mathrm{mM}$ glucose, and $1 \mathrm{mM}$ EDTA, pH 7.4) equal to that of the discarded plasma, centrifuged at $900 \mathrm{~g}$ for $6 \mathrm{~min}$ at room temperature, and resuspended at counts in the range of $1-5 \times 10^{8} / \mathrm{ml}$ in a Tyrode's buffer $(0.14 \mathrm{M} \mathrm{NaCl}, 2.7 \mathrm{mM} \mathrm{KCl}$, $1 \mathrm{mM} \mathrm{CaCl}_{2}, 12 \mathrm{mM} \mathrm{NaHCO}_{3}$, and $0.4 \mathrm{mM} \mathrm{NaH}_{2} \mathrm{PO}_{4}$ ) containing 5 $\mathrm{mM}$ glucose, $3.5 \mathrm{mg} / \mathrm{ml}$ bovine serum albumin, and $10 \mathrm{mM}$ Hepes, $\mathrm{pH}$ 7.4. Platelet counts were determined by phase-contrast microscopy. When trace amounts of ${ }^{125}$ I-fibrinogen or ${ }^{125} \mathrm{I}$-vWF were added to the PRP, $>99 \%$ of these proteins were removed by the washing procedure. Further properties of platelets washed and resuspended in this manner have been previously reported (12). Suspensions of washed platelets showed full aggregation only in the presence of $600 \mathrm{nM}$ (final) of added fibrinogen. Therefore, this concentration of fibrinogen was used in all the aggregation studies in which washed platelets were employed. For both PRP and platelets in suspension, aggregation was measured as percent light transmittance 3 min after the addition of the stimulus in on ELVI 840 aggregometer (Elvi-Logos, Milano, Italy). Platelet retention on glass microbeads was determined using a pump system (Adeplat " $S$ "; MasciaBrunelli, Milano, Italy). For this study, 5-7 ml of blood were drawn from the antecubital vein through a 19-gauge butterfly infusion set into a series of $20 \mathrm{ml}$ Terumo syringes containing heparin $(50 \mu \mathrm{l}$ of a $1-\mathrm{U} /$ $\mathrm{ml}$ solution) or heparin plus patient's paraprotein $(50 \mu \mathrm{g} / \mathrm{ml})$. After gentle mixing, the syringes were placed in the infusion pump and adhesion to glass microbeads was determined and quantified according to the manufacturer's recommendations.

Purification of patient's paraprotein. Electrophorectic and immunoelectrophoretic studies showed the presence of a monoclonal $\mathrm{IgG}_{1}$ kappa peak in the serum of the patient. For further studies, patient's paraprotein was first isolated by nitrocellulose paper chromatography, then eluted with phosphate buffer, $0.015 \mathrm{M}, \mathrm{pH} 7.4$, and dialyzed overnight at $4^{\circ} \mathrm{C}$ and finally applied to a $2 \times 20$-cm DEAE column preequilibrated with the same buffer. Elution was performed with $300-400$ $\mathrm{ml}$ of phosphate buffer, $\mathrm{pH} 7.4$, in a gradient from 0.015 to $0.30 \mathrm{M}$, as recommended by Fahey and Terry (14). Patient's paraprotein eluted from the column at low phosphate molarity $(0.015-0.060)$. At this low molarity only immunoglobulins of the $G$ type are eluted (14). Confirmation of the purity of the preparation was obtained when the eluted paraprotein was incubated overnight at $4^{\circ} \mathrm{C}$ in polystyrene micro-wells and the coated solid phase was allowed to react with monoclonal mouse immunoglobulins against human $\operatorname{IgG}_{1}, \mathrm{IgG}_{3}$, and $\operatorname{lgG}_{4}$. After $3 \mathrm{~h}$ of incubation at room temperature, purified goat anti-mouse $F\left(a b^{1}\right)_{2}$ fragments coupled with alkaline phosphatase were added and, after an additional $3 \mathrm{~h}$ incubation at room temperature, $p$-nitrophenyl-phosphate was added. The reaction was stopped 30 min later by adding $3 \mathrm{~N} \mathrm{NaOH}$. These studies showed a strong colored reaction only in the wells in which anti $\mathrm{IgG}_{1}$ antibodies had been added. $\mathrm{IgG}_{1}$ paraproteins from the sera of two other patients with multiple myeloma and no bleeding tendency were purified and characterized in a similar fashion and used as a control throughout. Immunoglobulins $\mathrm{G}$ from the sera of normal subjects were purified according to Fahey and Terry (14) and $\operatorname{IgG}_{1}$ subclasses were separated from $\mathrm{IgG}_{2}$ in a protein A-Sepharose column according to $\mathrm{Du}$ hamel et al. (15). No quantitative or qualitative differences in the results were found when the paraproteins were purified as reported above or isolated from the serum on a protein A-Sepharose column (15).

$F\left(a b^{l}\right)_{2}$ preparation. Purified paraprotein was dialyzed overnight at $4^{\circ} \mathrm{C}$ against a $0.2-\mathrm{M}$ sodium acetate solution pH 4.1 after which freshly prepared pepsin $(1 \mathrm{mg} / \mathrm{ml})$ was added in an amount equal to $2 \%$ of the antibody's weight and the solution was incubated at $37^{\circ} \mathrm{C} .18 \mathrm{~h}$ later, digestion was stopped by centrifuging the solution at $4,000 \mathrm{rpm}$ for 10 min at $4^{\circ} \mathrm{C}$, neutralizing the supernatant with $\mathrm{NaOH} 1 \mathrm{~N}$, and dialyzing against citrate-phosphate buffer, $\mathrm{pH}$ 7. Residual $\mathrm{Fc}$ fragments and intact immunoglobulins were removed on a protein A-Sepharose column. Both patient's paraprotein and its $\mathrm{F}\left(\mathrm{ab}^{1}\right)_{2}$ fragments showed a single band of $160,000 \mathrm{~mol} \mathrm{wt}$ and 105,000 mol wt, respectively, when electrophoresed in a $7.5 \%$ SDS-polyacrylamide gel (16).

Paraprotein iodination and binding to human platelets. Intact paraprotein as well as its $\mathrm{F}\left(\mathrm{ab}^{1}\right)_{2}$ fragments were labeled by the iodine monochloride method as previously described for murine monoclonal antibodies (17). Specific activities of these preparations were $4.3 \times 10^{4} \mathrm{cpm} /$ $\mu \mathrm{g}$ for the intact paraprotein and $3.3 \times 10^{4} \mathrm{cpm} / \mu \mathrm{g}$ for $\mathrm{F}\left(\mathrm{ab}^{1}\right)_{2}$ fragments. For time-dependent binding studies, aliquots $(3 \mathrm{ml})$ of unstirred platelets $\left(1-5 \times 10^{8}\right.$ platelets $\left./ \mathrm{ml}\right)$ in PRP or in suspensions of washed cells were incubated at room temperature $\left(22^{\circ} \mathrm{C}\right)$ with $\mathrm{AA}(10 \mu \mathrm{M})$ or microliter amounts of buffer. After a 3-min incubation, labeled paraprotein was added at a final concentration of $10 \mu \mathrm{g} / \mathrm{ml}$ and, at intervals between 1 and $15 \mathrm{~min}, 0.4 \mathrm{ml}$ of the suspension was removed and layered onto 50 $\mu \mathrm{l}$ of silicone oil in a $0.5 \mathrm{ml}$ of micro-Eppendorf tube. Free and plateletbound ligand were separated by centrifugation for $2 \mathrm{~min}$ at $12,000 \mathrm{~g}$ in an Eppendorf centrifuge and counted in a Beckman DP 5,500 gammacounter (DP 5,500; Beckman Instruments, Inc.). For dose-response studies, $500-\mu \mathrm{l}$ aliquots of unstirred platelets were incubated with $10 \mu \mathrm{M}$ AA or equal volumes of buffer for $3 \mathrm{~min}$, after which labeled paraprotein was added in final concentrations between 1 and $128 \mu \mathrm{g} / \mathrm{ml}$. Binding was determined 1 min later. Specific binding was calculated by subtracting the binding measured in the presence of a 20-fold excess of unlabeled paraprotein from the total. This latter nonspecific binding represented $1.73 \pm 0.07 \%$ of the total radioactivity bound. Binding was not corrected for the radioactivity trapped as determined by adding trace amounts of ${ }^{14} \mathrm{C}$-inulin. Trapping never exceeded $0.5 \%$ of the total bound.

Effect of patient's paraprotein on aggregation, secretion, and fibrinogen and $v W F$ binding to platelets. Increasing amounts (from 1 to $128 \mu \mathrm{g}$ / $\mathrm{ml}$, final) of patient's paraprotein or $500 \mu \mathrm{g} / \mathrm{ml}$ of control antibodies were incubated with $0.5 \mathrm{ml} \mathrm{PRP} \mathrm{(or} \mathrm{washed} \mathrm{platelets} \mathrm{in} \mathrm{suspension)} \mathrm{that}$ had been stirring at $1,000 \mathrm{rpm}$ for $1 \mathrm{~min}$ at $37^{\circ} \mathrm{C}$. After a further minute of stirring the agents were added and 1 min later, buffer (or fibrinogen, $600 \mathrm{nM}$ final) was added. In parallel, unlabeled patient's paraprotein, in concentrations ranging from 1 to $128 \mu \mathrm{g} / \mathrm{ml}$, were incubated with platelet suspensions in the absence of stirring at $22^{\circ} \mathrm{C}$. After $1 \mathrm{~min}$, the aggregating agent was added and after a further minute, ${ }^{125} \mathrm{I}$-fibrinogen $(600 \mathrm{nM}$, final) or ${ }^{125} \mathrm{I}-\mathrm{vWF}(20 \mu \mathrm{g} / \mathrm{ml}$, final) were added. Binding of the ligands was measured after $5 \mathrm{~min}$ for fibrinogen and after $45 \mathrm{~min}$ for vWF (12). When thrombin was the stimulus employed to expose binding sites for fibrinogen, hirudin $(0.1 \mathrm{U} / \mathrm{ml})$ was used to prevent clotting and was added simultaneously with fibrinogen. In other studies, platelet suspensions $\left(1-5 \times 10^{8} / \mathrm{ml}\right)$ were incubated at room temperature for $1 \mathrm{~min}$ with $50 \mu \mathrm{g} / \mathrm{ml}$ of patient's paraprotein or buffer after which $10 \mathrm{mU} / \mathrm{ml}$ thrombin, $10 \mu \mathrm{M} \mathrm{AA}$, or $1.5 \mathrm{mg} / \mathrm{ml}$ ristocetin were added. $3 \mathrm{~min}$ later, increasing concentrations of ${ }^{125} \mathrm{I}$-fibrinogen (from 37.5 to $1,200 \mathrm{nM}$ final) or ${ }^{125} \mathrm{I}-\mathrm{vWF}$ (from 1.25 to $40 \mu \mathrm{g} / \mathrm{ml}$ ) were added, and at appropriate time-intervals ( $5 \mathrm{~min}$ for fibrinogen and $45 \mathrm{~min}$ for vWF), free and platelet-bound ligands were separated in silicone oil and counted. When ristocetin was the stimulus, formaldehyde-fixed platelets were used.

Studies on specificity of patient's paraprotein. Patient's paraprotein specificity was determined as described in detail elsewhere for a murine monoclonal antibody (17). Briefly, $6 \times 10^{9}$ washed platelets in $1.5 \mathrm{ml}$ 
Tyrode's buffer $\mathrm{pH} 7.4$ were radiolabeled with $2 \mathrm{mCi}$ of ${ }^{125} \mathrm{I}$ by reacting with $2 \mathrm{mg}$ of lactoperoxidase (18), washed twice, resuspended in Tyrode's buffer containing $\mathrm{Ca}^{2+}(1 \mathrm{mM})$ or EDTA $10 \mathrm{mM}$ (pH 7.4 or 8.7$)$, and lysed at $4^{\circ} \mathrm{C}$ with $0.5 \%$ of Nonidet $\mathrm{P} 40.15 \mathrm{~min}$ after the addition of Nonidet P40, the lysate was centrifuged at $12,000 \mathrm{~g}$ for $15 \mathrm{~min}$ and aliquots of the supernatant (containing $\sim 10^{6} \mathrm{cpm}$ ) were incubated at $4^{\circ} \mathrm{C}$ with $25 \mu \mathrm{l}$ of patient's paraprotein. $18 \mathrm{~h}$ later the complexed antigen was bound to $25 \mu \mathrm{l}$ of protein A-Sepharose $(0.2 \mathrm{~g} / \mathrm{ml})$ and after $6 \mathrm{~h}$ at $4^{\circ} \mathrm{C}$ the pellet was washed extensively with Tyrode's buffer and the bound protein was released by adding $3 \%$ SDS with or without $0.2 \mathrm{M}$ DTT and heating to $100^{\circ} \mathrm{C}$ for $3 \mathrm{~min}$. After centrifuging the sample at $12,000 \mathrm{~g}$ for $5 \mathrm{~min}$, amounts of the supernatant (containing $\sim 30 \mu \mathrm{g}$ of protein) were electrophoresed on a $7.5 \%$ SDS polyacrylamide gel according to Laemmli (16). Molecular weight standards were run on each gel. Gels were run at $40 \mathrm{~mA}$ constant current until the front (visible as refractive index difference) reached the bottom of the gel. Running time was 4-5 h. Gels were then stained with Coomassie Blue, dried, autoradiographed, and identified after $1 \mathrm{wk}$ of development at $-70^{\circ} \mathrm{C}$. The blue-stained bands of the molecular weight standards were used to determine the approximate relative molecular weight $\left(M_{\mathrm{r}}\right)$ of the bands recorded on the autoradiograms. In another series of studies $5 \times 10^{9}$ washed platelets were incubated at $4^{\circ} \mathrm{C}$ in a buffer containing $0.15 \mathrm{M} \mathrm{NaCl}, 0.02 \mathrm{M}$ Tris, $2.5 \mathrm{mM}$ EDTA, pH 7.4, $1 \mathrm{mM}$ PMSF, $0.2 \mathrm{M}$ DTT, and 1\% Triton, $\mathrm{pH}$ 7.5. $15 \mathrm{~min}$ later, the solubilized platelet suspension was centrifuged at $40,000 \mathrm{~g}$ for $60 \mathrm{~min}$ at $4^{\circ} \mathrm{C}$ and the supernatant applied to a $1 \times 4-\mathrm{cm}$ column containing $5 \mathrm{mg}$ of patient's paraprotein coupled to $4 \mathrm{ml}$ of cyanogen-bromide-activated Sepharose. This column had been preequilibrated with the same buffer in which solubilized platelets were resuspended. After extensive washing of the column, the affinity-bound proteins were eluted with $5 \mathrm{ml}$ of a $3 \%$ SDS solution, heated to $100^{\circ} \mathrm{C}$ for $3 \mathrm{~min}$, and subjected to a $7.5 \%$ SDS polyacrylamide gel electrophoresis (16).

Clinical summary. The patient was a 62-yr-old white male in good health until December 1982, when he began to have bone pain and bleeding tendency (easy bruising, nose and gum bleeding) and noted an $8-\mathrm{kg}$ weight loss. He had no past history of spontaneous bleeding or excessive blood loss following surgery. On physical examination he had petechiae of the arms and legs, diffuse bone pain, splenomegaly, and hepatomegaly without lymphatic involvement. His blood counts showed: hemoglobin, $7.8 \mathrm{~g} / \mathrm{dl}$; platelets, $110,000 / \mu \mathrm{l}$; leukocytes, $10,500 / \mu \mathrm{l}$, with $53 \%$ neutrophils, $2 \%$ bands, $35 \%$ lymphocytes, $2 \%$ atypical lymphocytes, and $8 \%$ monocytes. His SMA $_{12}$ (Sequential Multiple Analyzer, Technicon) as well as activated and nonactivated thromboplastin time, prothrombin time, thrombin time, fibrinogen, and fibrinogen degradation products were all within normal ranges. Skeletal roentgenograms showed diffuse osteolytic lesions. Bone biopsy showed a hypoplastic marrow infiltrated with plasma cells ( $>35 \%$ ). There was an IgG kappa monoclonal paraprotein present in his serum (but not in urine) with a concentration ranging between 2.7 and $3.8 \mathrm{~g} / \mathrm{dl}$ during the course of the illness. Stools were always $3+$ guaiac positive. Endoscopy showed the presence of a gastric ulcer and the patient was given $\mathbf{4 0 0} \mathrm{mg}$ cimetidine twice daily. This treatment reduced the bleeding but only partially. The patient died $8 \mathrm{wk}$ after the diagnosis from massive gastrointestinal bleeding. At autopsy he had multiple myeloma, gastric ulcer, and evidence of external and internal (mainly gastrointestinal) hemorrhages.

\section{Results}

Patient's platelet test. Results of the screening tests in PRP from the patient are shown in Table I. Platelet aggregation in response to ADP or epinephrine was almost suppressed and that in response to collagen was markedly reduced. In one experiment in which higher concentrations of collagen and ADP were employed, it was found that the response to collagen $(5 \mu \mathrm{g} / \mathrm{ml})$ was $46 \%$ of normal and the response to ADP $(50 \mu \mathrm{M})$ was only $8 \%$ of normal. In contrast, agglutination in response to ristocetin and ATP secretion and $\mathrm{TxB}_{2}$ synthesis in response to thrombin
Table I. Screening Tests on Patient's Platelets

\begin{tabular}{|c|c|c|}
\hline Test & Patient & Controls \\
\hline \multicolumn{3}{|c|}{ Aggregation by ADP } \\
\hline$(10 \mu \mathrm{M})$ & $3.6 \pm 1.3$ & $67.5 \pm 7.3$ \\
\hline \multicolumn{3}{|c|}{ Aggregation by epinephrine } \\
\hline$(20 \mu \mathrm{M})$ & $2.2 \pm 4.1$ & $62.5 \pm 3.8$ \\
\hline \multicolumn{3}{|c|}{ Aggregation by collagen } \\
\hline$(1 \mu \mathrm{g} / \mathrm{ml})$ & $27.9 \pm 5.4$ & $65.4 \pm 6.7$ \\
\hline \multicolumn{3}{|c|}{ Agglutination by ristocetin } \\
\hline$(1.5 \mathrm{mg} / \mathrm{ml})$ & $49.3 \pm 10.3$ & $68.4 \pm 10.5$ \\
\hline \multicolumn{3}{|c|}{$\mathrm{TxB}_{2}$ synthesis by thrombin } \\
\hline$(1 \mathrm{U} / \mathrm{ml})$ & $416 \pm 100.7$ & $378 \pm 97.2$ \\
\hline \multicolumn{3}{|c|}{$\mathrm{TxB}_{2}$ synthesis by $\mathrm{AA}$} \\
\hline$(0.8 \mathrm{mM})$ & $1700 \pm 398$ & $1803 \pm 349$ \\
\hline \multicolumn{3}{|c|}{ ATP secretion by thrombin } \\
\hline$(1.0 \mathrm{U} / \mathrm{ml})$ & $2.5 \pm 0.6$ & $2.4 \pm 0.8$ \\
\hline \multicolumn{3}{|c|}{ ATP secretion by AA } \\
\hline$(0.8 \mathrm{mM})$ & $1.6 \pm 0.2$ & $1.8 \pm 0.3$ \\
\hline
\end{tabular}

Platelet aggregation and agglutination were measured as percent maximal light transmittance $3 \mathrm{~min}$ after the addition of the stimulus and adjusting the aggregometer so that PRP and platelet-poor plasma produced 10 and $90 \%$ light transmittance, respectively; $\mathrm{TxB}_{2}$ synthesis was measured by radioimmunoassay in aliquots of stirred $(1,000 \mathrm{rpm})$ samples $3 \mathrm{~min}$ after the addition of the stimulus and expressed as pmol $\mathrm{TxB}_{2} / 3 \times 10^{8}$ platelets; secretion of ATP was determined in a lumi-aggregometer by using luciferin-luciferase reagent $(50 \mu \mathrm{l}$ of a 10 $\mathrm{mg} / \mathrm{ml}$ solution) and expressed as $\mu \mathrm{mol}$ ATP secreted $/ 10^{11}$ platelets. The values reported for the patient are means \pm SEM of three determinations; those for controls are composite data from seven PRPs studied. A significant difference $(P<0.01)$ was always found when the data relative to the aggregation of platelets from the patient were compared with those from controls. In all the other determinations the $P$ value was always $>0.05$.

or AA were within normal ranges. As with ADP, shape change in response to collagen was entirely normal (not shown).

Effect of the addition of patient's paraprotein to normal PRP. Addition of the patient's purified IgG $_{1}$ kappa to normal PRP (adjusted with PFP to platelet counts of 90,000-120,000/ $\mathrm{l}$ ) caused all the platelet abnormalities seen in the patient's PRP. Furthermore, when added to the sample for at least $1 \mathrm{~min}$ before each test, the paraprotein also inhibited platelet adhesion to glass beads and fibrin clot retraction. Maximal impairment of platelet adhesion, aggregation, and clot retraction was achieved at paraprotein concentrations of $50 \mu \mathrm{g} / \mathrm{ml}$. Results of seven sets of experiments in which these concentrations of paraprotein were employed are summarized in Table II. Up to $128 \mu \mathrm{g} / \mathrm{ml}$ the inhibitory effect of patient's paraprotein was not accompanied by changes in platelet shape change (not shown) or intraplatelet levels of cAMP $\left(73.2+21.7 \mathrm{pmol} / 10^{9}\right.$ cells in buffer-treated platelets vs $91.9+32.2$ in platelets pretreated with $50 \mu \mathrm{g} / \mathrm{ml}$ of patient's paraprotein, $P>0.05$ ). Inhibition of ATP secretion and $\mathrm{TxB}_{2}$ formation in PRP depended on the dose of the agonist used, with marked effect at low doses and little effect when higher doses were employed. Similar results were found in suspensions of washed platelets $\left(1 \times 10^{8} / \mathrm{ml}\right)$ when $10-40 \mu \mathrm{M}$ AA or $10-40$ $\mathrm{mU} / \mathrm{ml}$ thrombin were employed. In addition, normal secretion of ATP (i.e., $3.2 \pm 0.5 \mu \mathrm{M}$ ) was observed when unstirred PRP, pretreated with $50 \mu \mathrm{g} / \mathrm{ml}$ of patient's paraprotein, was incubated 
Table II. Effect of Addition of Patient's Paraprotein to Normal PRP in Platelet Screening Tests

\begin{tabular}{|c|c|c|}
\hline Test & $\mathrm{IgG}_{1}$ & Buffer \\
\hline Platelet adhesion & $16.3 \pm 3.6$ & $86.5 \pm 10.2$ \\
\hline \multicolumn{3}{|c|}{ Clot retraction by thrombin } \\
\hline$(1 \mathrm{U} / \mathrm{ml})$ & $18.6 \pm 2.1$ & $96.5 \pm 2.3$ \\
\hline \multicolumn{3}{|c|}{ Aggregation by ADP } \\
\hline$(10 \mu \mathrm{M})$ & $6.8 \pm 3.4$ & $67.5 \pm 7.3$ \\
\hline \multicolumn{3}{|c|}{ Aggregation by epinephrine } \\
\hline$(20 \mu \mathrm{M})$ & $5.1 \pm 1.3$ & $62.5 \pm 3.8$ \\
\hline \multicolumn{3}{|c|}{ Aggregation by collagen } \\
\hline$(1 \mu \mathrm{g} / \mathrm{ml})$ & $12.4 \pm 5.8$ & $65.4 \pm 6.7$ \\
\hline \multicolumn{3}{|c|}{ Aggregation by AA } \\
\hline$(0.5 \mathrm{mM})$ & $10.5 \pm 3.1$ & $80.5 \pm 10.3$ \\
\hline \multicolumn{3}{|c|}{ Agglutination by ristocetin } \\
\hline$(1.5 \mathrm{mg} / \mathrm{ml})$ & $58.3 \pm 6.5$ & $68.4 \pm 10.5$ \\
\hline \multicolumn{3}{|c|}{$\mathrm{TxB}_{2}$ synthesis by thrombin } \\
\hline$(0.1 \mathrm{U} / \mathrm{ml})$ & $21.5 \pm 8.2$ & $96.5 \pm 12.3$ \\
\hline \multicolumn{3}{|c|}{$\mathrm{TxB}_{2}$ synthesis by thrombin } \\
\hline$(1 \mathrm{U} / \mathrm{ml})$ & $400 \pm 78.3$ & $378 \pm 97.2$ \\
\hline \multicolumn{3}{|c|}{$\mathrm{TxB}_{2}$ synthesis by AA } \\
\hline$(0.5 \mathrm{mM})$ & $75.2 \pm 13.4$ & $336.8 \pm 79.3$ \\
\hline \multicolumn{3}{|c|}{$\mathrm{TxB}_{2}$ synthesis by $\mathrm{AA}$} \\
\hline$(0.8 \mathrm{mM})$ & $1740 \pm 316$ & $1803 \pm 349$ \\
\hline \multicolumn{3}{|c|}{ ATP secretion by thrombin } \\
\hline$(0.1 \mathrm{U} / \mathrm{ml})$ & $0.7 \pm 0.3$ & $1.7 \pm 0.4$ \\
\hline \multicolumn{3}{|c|}{ ATP secretion by thrombin } \\
\hline$(1.0 \mathrm{U} / \mathrm{ml})$ & $2.7 \pm 0.1$ & $2.4 \pm 0.8$ \\
\hline \multicolumn{3}{|c|}{ ATP secretion by AA } \\
\hline$(0.5 \mathrm{mM})$ & $0.5 \pm 0.3$ & $1.7 \pm 0.2$ \\
\hline \multicolumn{3}{|c|}{ ATP secretion by AA } \\
\hline$(0.8 \mathrm{mM})$ & $2.0 \pm 0.4$ & $1.8 \pm 0.3$ \\
\hline
\end{tabular}

Platelet adhesion to glass microbeads was determined in an Adeplat " $\mathrm{S}$ " system employing blood freshly drawn into syringes containing heparin or heparin plus patient's paraprotein; fibrin clot retraction was calculated by relating the volume of serum extruded at $60 \mathrm{~min}$ to the total amount of the initial mixture (PRP + thrombin) and expressed as a percentage; methods employed for studying and measuring platelet aggregation, agglutination, $\mathrm{TxB}_{2}$ synthesis, and $\mathrm{ATP}$ secretion are given in the legend of Table I. Each value is the mean \pm SEM of composite data from seven PRPs studied. Addition of the antibody had no effect ( $P$ always $>0.05)$ on the agglutination of platelets in response to ristocetin as well as on the secretion of ATP and the synthesis of $\mathrm{TxB}_{2}$ in response to high concentrations of thrombin or AA. In all the other studies patient's paraprotein significantly affected platelet function $(P$ always $<0.01)$.

with $5 \mathrm{mM}$ EDTA for $5 \mathrm{~min}$ before the addition of A23187 (50 $\mu \mathrm{M})$. These data are similar to those obtained using platelets from thrombasthenic patients (12) and comparable to those obtained by incubating normal platelets with a murine monoclonal antibody to the glycoprotein IIb-IIIa complex (GPIIb-IIIa) (19) and were interpreted to suggest that the aggregation of platelets may act to enhance secretion of nucleotides and $\mathrm{TxB}_{2}$ synthesis when low doses of agonists are used, whereas at higher doses secretion and $\mathrm{TxB}_{2}$ formation are largely independent of aggregation. Similar results were found when equimolar concentrations of $F\left(a b^{1}\right)_{2}$ fragments of patient's paraprotein were employed. In contrast, concentrations of the two control parapro- teins or normal $\mathrm{IgG}_{1}$ as high as $500 \mu \mathrm{g} / \mathrm{ml}$ did not affect platelet adhesion, aggregation, secretion, $\mathrm{TxB}_{2}$ synthesis, and clot retraction.

Binding of ${ }^{125}$ I-patient's paraprotein to platelets. Both in PRP and washed platelets in suspension binding of radiolabeled monoclonal paraprotein to unstimulated or stimulated platelets was complete in $1 \mathrm{~min}$. Up to $15 \mathrm{~min}$ incubation, $>97 \%$ of the labeled ligand could be displaced within $10 \mathrm{~min}$ by a 20 -fold excess of unlabeled paraprotein. The extent of the binding was the same in PRP and platelets washed free of fibrinogen as well as in the presence or absence of EDTA $(10 \mathrm{mM})$. Estimates of the affinity determined as recommended by $\operatorname{Klotz}(20)$ and Coller et al. (19) showed that at saturating levels of added ligand (i.e., $10-15 \mu \mathrm{g} / \mathrm{ml}$ for the inflection point and $30-50 \mu \mathrm{g} / \mathrm{ml}$ for maximal binding) the paraprotein bound to an average of 35,523 sites/cell (1 SEM $=3,476$ ) in PRP from normals (Fig. 1) (apparent dissociation constant, $16.4 \pm 3.9 \mu \mathrm{g} / \mathrm{ml}$ ) and to $1,989 \pm 284$ sites/cell in PRP from a thrombasthenic patient. Laboratory studies on the platelets from this patient have been previously reported (12).

Effect of the addition of patient's paraprotein of ${ }^{125}$ I-fibrinogen, ${ }^{125} I-v W F$, and $\left[{ }^{3} H\right] P G E_{l}$ binding to platelets. Addition of purified $\operatorname{IgG}_{1}$ kappa to washed platelets inhibited in a concentration-dependent fashion the binding of ${ }^{125} \mathrm{I}$-fibrinogen in response to thrombin or AA. Maximal inhibition was found at concentrations of added paraprotein of $50 \mu \mathrm{g} / \mathrm{ml}$. Results of eight sets of experiments in which this concentration of inhibitor was employed are summarized in Table III and are similar to those found when higher concentrations of thrombin and AA (i.e., $40 \mathrm{mU} / \mathrm{ml}$ for thrombin and $40 \mu \mathrm{M}$ for AA) were used. To further characterize inhibition of fibrinogen binding by patient's paraprotein, platelets in suspension were incubated at room temperature with a single concentration of the inhibitor $(50 \mu \mathrm{g} / \mathrm{ml})$ or buffer. AA $(10 \mu \mathrm{M})$ was added 1 min later and

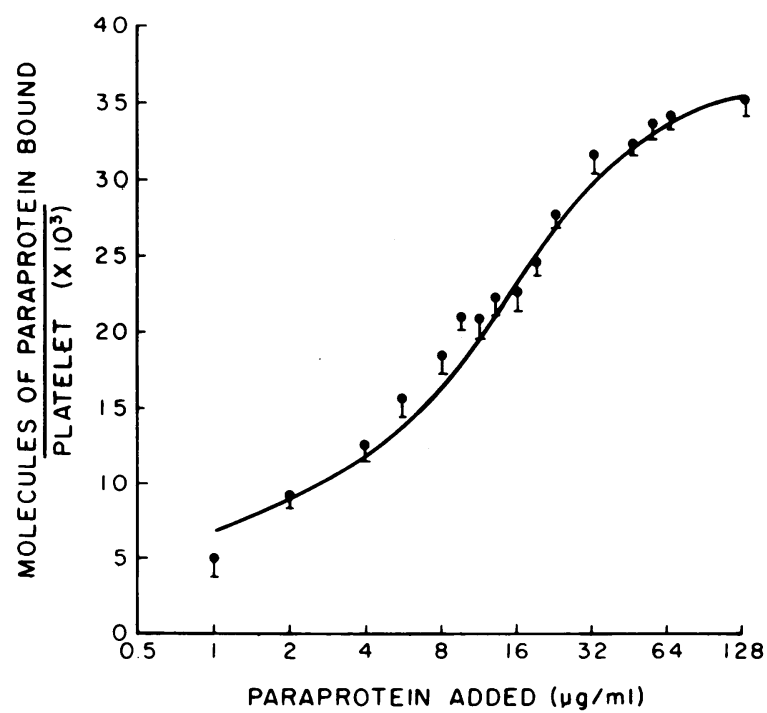

Figure 1. Specific binding of ${ }^{125}$ I-patient's paraprotein to platelets in PRP. Aliquots of unstirred platelets in PRP were incubated at $22^{\circ} \mathrm{C}$ with AA $(10 \mu \mathrm{M})$ or microliter amounts of buffer. After a 3-min incubation, labeled paraprotein was added in final concentrations between 1 and $128 \mu \mathrm{l} / \mathrm{ml}$. Binding was determined $1 \mathrm{~min}$ later and plotted according to $\operatorname{Klotz}(19,20)$. The data reported are means \pm SEM of seven different PRP tested. 
fibrinogen binding was measured as a function of ${ }^{125} \mathrm{I}$-fibrinogen concentration employed. Analysis of the data by using double reciprocal plots was consistent with a noncompetitive inhibition of the binding by the paraprotein (Fig. 2). Selectivity of the inhibition of fibrinogen binding by the paraprotein was then determined by evaluating the effects of the inhibitor on the binding of $\mathrm{PGE}_{1}$ and vWF to platelets. The former was studied because a murine monoclonal antibody (B59.2) to the platelet receptor for fibrinogen does not affect the binding of this prostaglandin to resting platelets (unpublished observations of the authors); the latter was chosen since the presumed receptor for fibrinogen on the platelet surface is also one of the binding sites for vWF on these cells $(13,21,22)$. At concentrations between 50 and $128 \mu \mathrm{g} / \mathrm{ml}$ (final), purified monoclonal paraprotein did not affect the extent of the binding of radiolabeled $\mathrm{PGE}_{1}$ to resting platelets in PRP. At saturating levels of added $\mathrm{PGE}_{1}$ (i.e., at a final concentration of $300 \mathrm{nM}$ ), platelets preincubated for 1 min with 50 $\mu \mathrm{g} / \mathrm{ml}$ of patient's paraprotein bound $0.28 \pm 0.07$ pmol $P E_{1} /$ $10^{8}$ cells and platelets preincubated with equal microliter amounts of buffer bound $0.31 \pm 0.03$ pmol $P G E_{1} / 10^{9}$ cells $(P$ $>0.05$ ). When we studied the binding of vWF, we found that the paraprotein did not affect the interaction of this adhesive protein with platelets stimulated with ristocetin, while it impaired

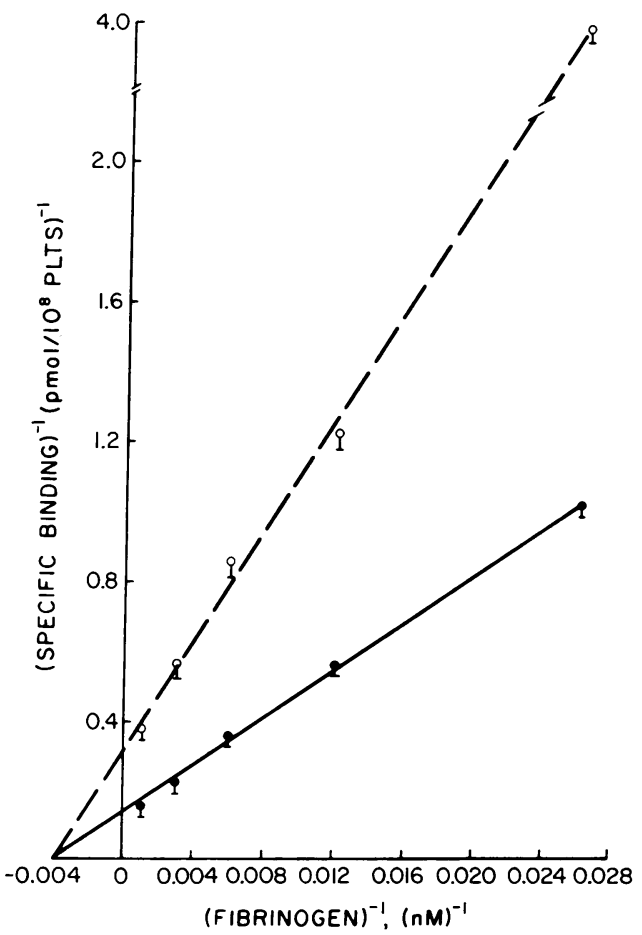

Figure 2. Inhibition of fibrinogen binding to AA-stimulated platelets by patient's paraprotein. Suspensions of $1-5 \times 10^{8}$ platelets $/ \mathrm{ml}$ were incubated at room temperature for $1 \mathrm{~min}$ with $50 \mu \mathrm{g} / \mathrm{ml}$ of patient's paraprotein (open circles) or buffer (closed circles) after which $10 \mu \mathrm{M}$ AA was added. 3 min later increasing concentrations of ${ }^{125}$ I-fibrinogen (from 37.5 to $1,200 \mathrm{nM}$, final) were added and $5 \mathrm{~min}$ later free and bound ligand were separated in silicone oil and counted. Specific binding was determined by subtracting from the total bound the radioactivity bound in the presence of a 20 -fold excess of cold fibrinogen. Nonspecific binding never exceeded $15 \%$. The data were then expressed in terms of double-reciprocal plot. Each point is the mean \pm SEM of four different platelet suspensions tested. Similar results were found when thrombin was the stimulus used. the binding in response to $10 \mathrm{mU} / \mathrm{ml}$ thrombin or $10 \mu \mathrm{M}$ AA (Table III). Similar results were found when higher concentrations of thrombin or AA (i.e., $40 \mathrm{mU} / \mathrm{ml}$ for thrombin and 40 $\mu \mathrm{M}$ for $\mathrm{AA}$ ) were used. Concentrations of control paraproteins or normal $\mathrm{IgG}_{1}$ as high as $500 \mu \mathrm{g} / \mathrm{ml}$ did not affect binding of fibrinogen or vWF in response to AA or thrombin (not shown).

Specificity of patient's paraprotein. The immunoprecipitate formed by the reaction of patient's paraprotein with radiolabeled platelet membrane glycoproteins was solubilized in 3\% SDS, reduced with $0.2 \mathrm{M}$ DTT, and autoradiographed. As shown in Fig. $3 \mathrm{~A}$, the inhibitor precipitated very close bands (apparent $\left.M_{\mathrm{r}}, \sim 116,000\right)$ in the presence of $\mathrm{Ca}^{2+}(1 \mathrm{mM})$ or EDTA $(10$ $\mathrm{mM}, \mathrm{pH}$ 7.4). These bands were not present in immunoprecipitates in which platelets from a thrombasthenic patient were used or in those in which platelets from normal donors were incubated with an $\mathrm{IgG}_{1}$ paraprotein from a patient with multiple myeloma and no bleeding tendency. Specificity of patient's paraprotein was further confirmed in affinity chromatography studies. After reduction, two peptides of 120,000 apparent $M_{\mathrm{r}}$ and 110,000 apparent $M_{\mathrm{r}}$ were eluted in addition to a faint band of $65,000 M_{\mathrm{r}}$ comigrating with albumin and in some samples to another band of $\sim 40,000 M_{\mathrm{r}}$ comigrating with actin. These minor bands were not present in immunoprecipitates and did not interact with the paraprotein in immunblots (24). However, it is worth mentioning that also the platelet antigens identified by the paraprotein in affinity chromatography as well as in immunoprecipitation studies were not recognized by the inhibitor in immunoblots, possibly because of the loss of the epitope during exposure to SDS and/or electrophoresis.

Published values $(19,23)$ for molecular weights of platelet

Table III. Effect of Patient's Paraprotein on ${ }^{125}$ I-Fibrinogen and ${ }^{125}$ I-vWF Binding to Stimulated Platelets

\begin{tabular}{|c|c|c|c|c|}
\hline \multirow[b]{2}{*}{ Stimulus } & \multicolumn{2}{|c|}{$\begin{array}{l}\text { Picomoles }{ }^{125} \text { I-fibrinogen } \\
\text { bound } / 10^{8} \text { platelets }\end{array}$} & \multicolumn{2}{|c|}{$\begin{array}{l}\text { Micrograms }{ }^{125} \mathrm{I}-\mathrm{vWF} \text { bound/ } \\
10^{8} \text { platelets }\end{array}$} \\
\hline & Buffer & $\lg _{1}$ & Buffer & $\operatorname{lgG}_{1}$ \\
\hline \multicolumn{5}{|l|}{ Thrombin } \\
\hline$(10 \mathrm{mU} / \mathrm{ml})$ & $10.1 \pm 1.6$ & $3.1 \pm 0.6^{*}$ & $15.1 \pm 3.8$ & $8.6 \pm 2.4^{*}$ \\
\hline $\mathrm{AA}(10 \mu \mathrm{M})$ & $6.2 \pm 1.5 \ddagger$ & $2.4 \pm 0.5^{*}$ & $3.9 \pm 0.2 \ddagger$ & $1.21 \pm 0.2^{*}$ \\
\hline \multicolumn{5}{|l|}{ Ristocetin } \\
\hline$(1.5 \mathrm{mg} / \mathrm{ml})$ & ND§ & ND§ & $16.7 \pm 2.9$ & $18.9 \pm 3.1$ \\
\hline
\end{tabular}

$* P<0.01$ buffer vs. paraprotein.

$\ddagger P<0.01$ thrombin vs. AA-induced binding (in the presence of buffer).

$\S \mathrm{ND}$, not detectable.

Platelet suspensions $\left(1-5 \times 10^{8} / \mathrm{ml}\right)$ were incubated for $1 \mathrm{~min}$ with 50 $\mu \mathrm{g} / \mathrm{ml}$ of patient's paraprotein or buffer after which $10 \mathrm{mU} / \mathrm{ml}$ thrombin or $10 \mu \mathrm{M}$ AA or $1.5 \mathrm{mg} / \mathrm{ml}$ ristocetin were added. $3 \mathrm{~min}$ later increasing concentrations of ${ }^{125} \mathrm{I}$-fibrinogen (from 37.5 to $1,200 \mathrm{nM}$ final) or ${ }^{125} \mathrm{I}-\mathrm{vWF}$ (from 1.25 to $40 \mu \mathrm{g} / \mathrm{ml}$ ) were added and at appropriate time intervals ( $5 \mathrm{~min}$ for fibrinogen and $45 \mathrm{~min}$ for vWF), free and platelet-bound ligands were separated in silicone oil and counted. When thrombin was employed to expose binding sites for fibrinogen, hirudin $(0.1 \mathrm{U} / \mathrm{ml})$ was used to prevent clotting. When ristocetin was the stimulus, formaldehyde-fixed platelets were used. In the presence of both buffer and patient's paraprotein fibrinogen binding reached saturation at $\sim 600 \mathrm{nM}$, while vWF at $\sim 20 \mu \mathrm{g} / \mathrm{ml}$ (final) of added protein. Each value is the mean \pm SEM of composite data from eight suspensions of platelets studied. 


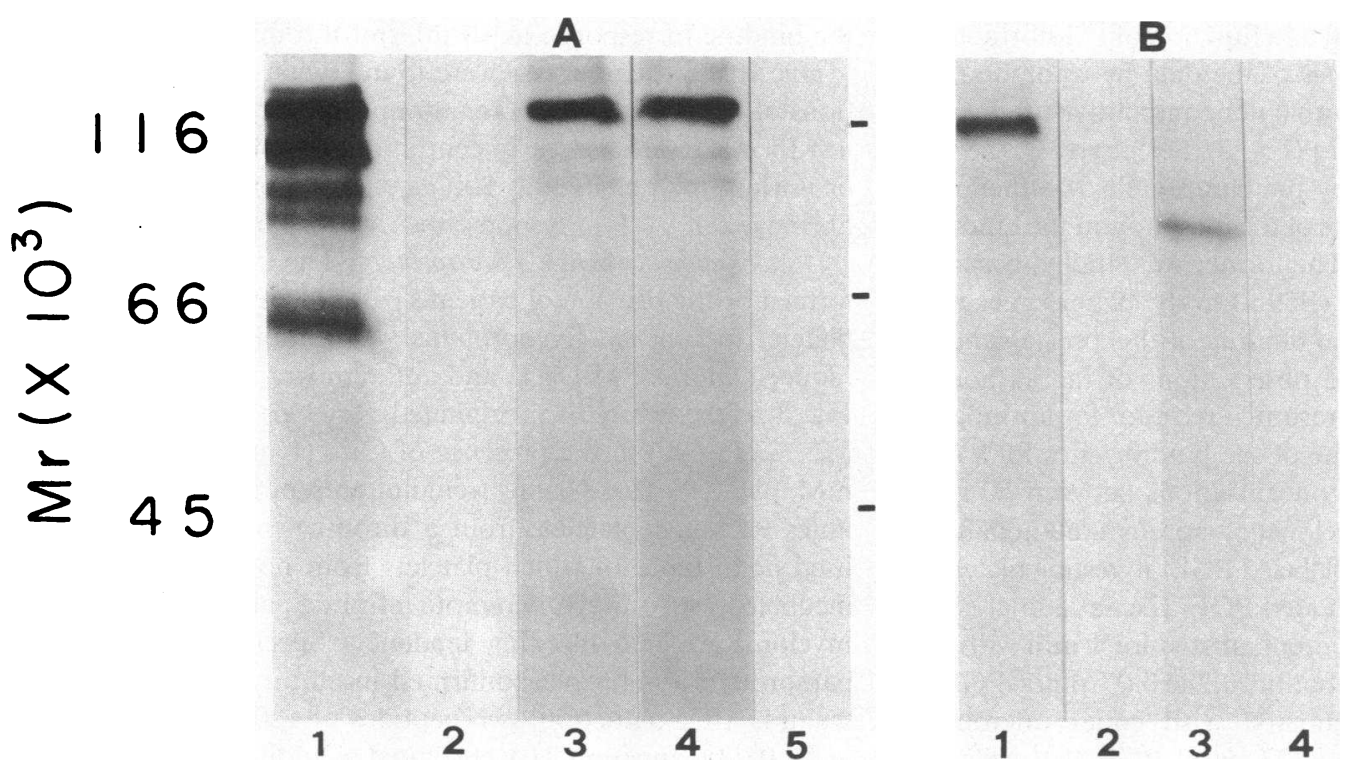

Figure 3. Autoradiograms of the platelet membrane proteins precipitated by patient's paraprotein. $A$, for these studies platelets were labeled with ${ }^{125}$ I, lysed, and incubated with the inhibitor as detailed in Methods. The immunoprecipitate was solubilized in $3 \%$ SDS, reduced with $0.2 \mathrm{M}$ DTT, and electrophoresed on a $7.5 \%$ polyacrylamide gel. Lane 1 contains the whole platelet preparation; lanes 3 and 4 contain the paraprotein's precipitate using platelets from normal donors incubated in the presence of $\mathrm{Ca}^{2+}(1 \mathrm{mM})$ and EDTA (10 mM, pH 7.4), respectively; lane 2 , the precipitate of platelets from a

thrombasthenic patient; and lane 5 , the precipitate of a paraprotein from another patient with multiple myeloma and no bleeding tendency. $B$, Similar to $A$ except that platelets were incubated at $22^{\circ} \mathrm{C}$ with $10 \mathrm{mM}$ EDTA pH 8.7. Lane 1 contains the paraprotein's precipitate in the presence of DTT; lane 2, the precipitate obtained employing a paraprotein from a patient with multiple myeloma and no bleeding tendency (different from that used in lane 5 of $A$ ); lane 3, the paraprotein's precipitate without reduction; and lane 4, the precipitate obtained using IgG, from the sera of normal donors.

glycoproteins suggest that the antigen identified by the paraprotein was the GPIIb-IIIa complex. This complex has been shown to be maximally dissociated by EDTA at $\mathrm{pH} 8.7$ or higher (2426). Therefore, to determine whether the paraprotein was directed to a single glycoprotein or to the complex, platelets were labeled with ${ }^{125} \mathrm{I}$, washed twice in Tyrode's buffer, and resuspended in the same buffer containing $10 \mathrm{mM}$ EDTA pH 8.7. The immunoprecipitate formed by the reaction of the paraprotein with platelets processed in this manner is shown in Fig. 3 $B$. A single band was present with a molecular weight of $\sim 115,000$ under reducing conditions (DTT, $0.2 \mathrm{M}$ ) and $\sim 90,000$ mol wt under nonreducing conditions. The higher molecular weight upon reduction is characteristic of GPIIIa $(19,23)$.

\section{Discussion}

Monoclonal paraproteins that induce hemostatic abnormalities have often been described in dysproteinemia. The immunoglobulin nature of these inhibitors has been established and their mechanism of action has been delineated (1-7). Platelet abnormalities in dysproteinemia have also been reported (8-11), but the mechanism of the effect of paraproteins in the impairment of platelet function is poorly understood. In a recent comprehensive review on this topic (1) it has been stated that ". . . abnormal monoclonal immunoglobulins occurring in dysproteinemias have no known physiologic specificity for the surface of the hemostatic components with which they react," and that ". . . the adherence of the paraprotein nonspecifically to the platelet surface appears to interfere with normal platelet function." Our findings suggest that impairment of platelet function in dysproteinemia may also be the result of a specific immunologic reaction of the paraprotein with platelets. Studies over the past years have suggested that monoclonal proteins are normal immunoglobulins produced in excessive quantities (27).
However, antibody activity has been clearly demonstrated for only a few of them (28). The paraprotein that we have isolated from our patient has antibody activity biochemically and functionally comparable to that of an antibody isolated from a polytransfused thrombasthenic patient $(29,30)$ or from patients with immune thrombocytopenia $(31,32)$.

Much evidence has been accumulated to indicate that GPIIbIIIa is the receptor for fibrinogen and vWF on platelets exposed to naturally occurring aggregating agents and that the interaction of fibrinogen and vWF with this complex is essential for effective hemostasis as well as for a variety of in vitro platelet functions (21). Patients with Glanzmann's thrombasthenia have a bleeding tendency (21) and platelets from these patients lack GPIIb-IIIa $(18,21,33)$ and exhibit negligible binding of fibrinogen after stimulation with $\operatorname{ADP}(30,34-37)$ and deficient binding of vWF when exposed to thrombin (22). Estimates of the affinity indicate that normal platelets have $\sim 39,000-50,000$ binding sites for fibrinogen $(12,17,19,21,34,35)$, a figure comparable to the number of GPIIb-IIIa complexes identified on the surface of normal platelets by specific monoclonal antibodies $(17,19,38-$ 41). GPIIb-IIIa may form complexes with fibrinogen (42), and murine monoclonal antibodies to GPIIb and/or IIIa inhibit aggregation as well as binding of fibrinogen or VWF to platelets $(13,17,19,38-40)$. Screening tests (Table I) in platelets from this patient showed abnormalities comparable to those described in Glanzmann's thrombasthenia (21). Most reports indicate that thrombasthenic platelets do not aggregate at all in response to collagen (21). However, studies by several investigators showed that small aggregates are, in fact, produced (43-46). Similar results are also obtained after in vitro addition to normal platelets of a monoclonal antibody to GPIIb-IIIa complex (19). It is unclear whether these aggregates are the result of platelet-platelet interactions or rather the adhesion of several platelets to collagen fibrils, which can simulate the appearance of an aggregate. The in vitro addition of purified paraprotein to normal platelets 
caused all the abnormalities observed in platelets from the patient and also impaired adhesion to glass beads, fibrin clot retraction, and binding of fibrinogen and vWF in response to thrombin or AA. Thus, it induced a thrombasthenic-like state in normal platelets. In addition, the paraprotein bound to normal platelets (Fig. 1) but only negligibly to platelets from a thrombasthenic patient; it reacted with GPIIb-IIIa on immunoprecipitates as well as on an antibody-coupled affinity column and it only inhibited the binding to platelets of agonists whose receptor is known to be GPIIb-IIIa.

The aggregation as well as the binding of fibrinogen and vWF to platelets requires exposure of the receptor, and thromboxane synthesis, nucleotide secretion, translocations of calcium ions across the membranes, and intracellular cAMP are thought to play a major role in this exposure $(21,47)$. Our data make it unlikely that patient's paraprotein acts by affecting one or more of these basic events. The ability of platelets to bind fibrinogen involves platelet activation as well as the presence of intact GPIIbIIIa complexes (21). Since the paraprotein only reacts with GPIIIa (Fig. $3 \mathrm{~B}$ ) and in detergent extracts GPIIb and GPIIIa from reversible heterodimer complexes $(48,49)$, one could postulate that patient's paraprotein impairs fibrinogen and vWF binding to platelets by inhibiting the formation of the complex. Our data are not consistent with this possibility since at physiological $\mathrm{pH}$ more than one band can be detected on unstimulated intact platelets even in the presence of EDTA (Fig. $3 A$ ). Therefore, it seems reasonable to conclude that patient's paraprotein induces platelet abnormalities by sterically hindering the association of fibrinogen and vWF with the GPIIb-IIIa.

These data show that bleeding occurring in dysproteinemia may be the result of a specific interaction of monoclonal paraproteins with platelets and support the concept that the interaction of fibrinogen and/or vWF with the GPIIb-IIIa is essential for effective hemostasis.

\section{Acknowledgments}

The authors thank Dr. M. J. Silver and Dr. C. Iride for helpful discussion, P. Thiagarajan for the immunoblots, and Catherine Kerwood for typing the manuscript. This work was supported in part by grant 8300396.04 from the Italian National Research Council (CNR).

\section{References}

1. Furie, B. 1982. Acquired coagulation disorders and dysproteinemias. In Hemostasis and Thrombosis-Basic Principles and Clinical Practice. R. W. Colman, J. Hirsh, V. J. Marder, and E. W. Salzman, editors. J.B. Lippincott Co., Philadelphia, PA. 577-581.

2. Thiagarajan, P., S. S. Shapiro, and L. DeMarco. 1980. Monoclonal immunoglobulin $\mathbf{M} \lambda$ coagulation inhibitor with phospholipid specificity: mechanism of a lupus anticoagulant. J. Clin. Invest. 66:397-405.

3. Shapiro, S. S., and M. Hultin. 1975. Acquired inhibitors to the blood coagulation factors. Semin. Thromb. Hemostasis. 1:336-385.

4. Lackner, H., V. Hunt, M. B. Zucker, and J. Pearson. 1970. Abnormal fibrin ultrastructure, polymerization and clot retraction in multiple myeloma. Br. J. Haematol. 18:625-636.

5. Coleman, M., E. M. Vigliano, M. E. Weksler, and R. L. Nachman. 1972. Inhibition of fibrin monomer polymerization by lambda myeloma globulins. Blood. 39:210-223.

6. Khoory, M. S., M. E. Nesheim, E. J. W. Bowie, and K. G. Mann. 1980. Circulating heparan sulfate proteoglycan anticoagulant from a patient with plasma cell disorder. J. Clin. Invest. 65:666-674.
7. Palmer, R. N., M. E. Rick, P. D. Rick, J. A. Zeller, and H. R. Gralnick. 1984. Circulating heparan sulfate anticoagulant in a patient with fatal bleeding disorder. N. Engl. J. Med. 310:1696-1699.

8. Vigliano, E. M., and H. I. Horowitz. 1967. Bleeding syndrome in a patient with IgA myeloma: interaction of protein and connective tissue. Blood. 29:823-836.

9. Perkins, H. A., M. R. MacKenzie, and H. H. Fudenberg. 1970. Hemostatic defects in dysproteinemias. Blood. 35:695-707.

10. Penny, R., P. A. Castaldi, and H. M. Whitsed. 1971. Inflammation and haemostasis in paraproteinemias. Br. J. Haematol. 20:35-44.

11. Lackner, H. 1973. Hemostatic abnormalities associated with dysprotidemias. Semin. Haematol. 10:125-133.

12. DiMinno, G., A. M. Cerbone, P. L. Mattioli, S. Turco, C. Iovine, and M. Mancini. 1985. Functionally thrombasthenic state in normal platelets following the administration of ticlopidine. J. Clin. Invest. 75: 328-338.

13. Ruggeri, Z. M., L. DeMarco, L. Gatti, R. Bader, and R. H. Montgomery. 1983. Platelets have more than one binding site for von Willebrand factor. J. Clin. Invest. 72:1-12.

14. Fahey, J. L., and E. W. Terry. 1978. Ion exchange chromatography and gel filtration. In Handbook of Experimental Immunology. D. M. Weir, editor. Blackwell Scientific Publications Inc., Oxford. 8:1-16.

15. Duhamel, R. C., P. H. Schur, K. Brendel, and E. Meezan. 1979. $\mathrm{pH}$ gradient elution of human $\mathrm{IgG}_{1}, \mathrm{IgG}_{3}$ and $\mathrm{IgG}_{4}$ from protein ASepharose. J. Immunol. Methods. 31:211-217.

16. Laemmli, U. K. 1970. Cleavage of structural proteins during the assembly of the head of bacteriophage T4. Nature (Lond.). 227:680-682.

17. DiMinno, G., P. Thiagarajan, B. Perussia, J. Martinez, S. Shapiro, G. Trinchieri, and S. Murphy. 1983. Exposure of fibrinogen binding sites by collagen, arachidonic acid and ADP. Inhibition by monoclonal antibody to the glycoprotein IIb-IIIa complex. Blood. 61:140-148.

18. Phillips, D. R., C. S. P. Jenkins, E. F. Luscher, and M. J. Larrieu. 1975. Molecular differences of exposed surface protein on thrombasthenic platelet plasma membranes. Nature (Lond.). 257:599-600.

19. Coller, B. S., E. I. Peerschke, L. E. Scudder, and C. A. Sullivan. 1983. A murine monoclonal antibody that completely blocks the binding of fibrinogen to platelets produces a thrombasthenic-like state in normal platelets and binds to glycoprotein IIb and/or IIIa. J. Clin. Invest. 72: 325-338.

20. Klotz, I. M. 1982. Numbers of receptor sites from Scatchard graphs: facts and fantasies. Science (Wash. DC) 217:1274-1279.

21. George, J. N., A. T. Nurden, and D. R. Phillips. 1984. Molecular defects in interactions of platelets with the vessel wall. N. Engl. J. Med. 311:1084-1098

22. Ruggeri, Z. M., R. Bader, and L. DeMarco. 1982. Glanzmann thrombasthenia: deficient binding of von Willebrand factor to thrombinstimulated platelets. Proc. Natl. Acad. Sci. USA. 79:6038-6041.

23. Phillips, D. R., and P. P. Agin. 1977. Platelet plasma membrane glycoproteins. Evidence for the presence of nonequivalent disulfide bonds using nonreduced-reduced two-dimensional gel electrophoresis. J. Biol. Chem. 252:2121-2126.

24. Thiagarajan, P., S. S. Shapiro, E. Levine, L. DeMarco, and A. Yalcin. 1985. A monoclonal antibody to human platelet glycoprotein IIIa detects a related protein on human endothelial cells. J. Clin. Invest. 75:896-901.

25. Gogstad, G. O., I. Hagen, M. B. Krutnes, and N. O. Solum. 1982. Dissociation of the glycoprotein IIb-IIIa complex in isolated human platelet membranes. Biochim. Biophys. Acta. 689:21-30.

26. Brass, L. F., S. J. Shattil, T. J. Kunicki, and J. S. Bennett. 1985. Effect of calcium on the stability of the platelet membrane glycoprotein IIb-IIla complex. J. Biol. Chem. 260:7875-7881.

27. Osterland, C. K., and L. R. Espinoza. 1975. Biological properties of myeloma paraproteins. Arch. Intern. Med. 135:32-36.

28. Seligmann, M., and J. C. Brouet. 1973. Antibody activity of human myeloma globulins. Semin. Hematol. 10:163-177.

29. Levy-Toledano, S., G. Tobelem, C. Legrand, R. Bredoux, L. 
Degos, A. Nurden, and J. P. Caen. 1979. Acquired IgG antibody occurring in thrombasthenic patients: its effects on human platelet function. Blood. 51:1065-1071.

30. Lee, H., A. T. Nurden, A. Thomaidis, and J. P. Caen. 1981. Relationship between fibrinogen binding and platelet glycoprotein deficiencies in Glanzmann's thrombasthenia type I and type II. Br. J. Haematol. 48:47-57.

31. Woods, V. L., E. H. Oh, D. Mason, and R. McMillan. 1984. Autoantibodies against the platelet glycoprotein IIb-IIIa complex in patients with chronic ITP. Blood. 62:368-375.

32. Beardsley, D. S., J. E. Spiegel, M. M. Jacobs, R. I. Handin, and S. E. Lux. 1984. Platelet membrane glycoprotein IIIa contains antigens that bind anti-platelet antibodies in immune thrombocytopenias. J. Clin. Invest. 74:1701-1707.

33. Nurden, A. T., and J. P. Caen. 1974. An abnormal platelet glycoprotein pattern in three cases of Glanzmann's thrombasthenia. Br. J. Haematol. 28:253-260.

34. Bennet, J. S., and G. Vilaire. 1979. Exposure of platelet fibrinogen receptors by ADP and epinephrine. J. Clin. Invest. 64:1393-1401.

35. Peerschke, E. I., M. B. Zucker, R. A. Grant, J. J. Egan, and M. M. Johnson. 1980. Correlation between fibrinogen binding to human platelets and platelet aggregability. Blood. 55:841-847.

36. Mustard, J. F., R. L. Kinlough-Rathbone, M. A. Packham, D. W. Perry, E. J. Harfenist, and K. R. M. Pai. 1979. Comparison of fibrinogen association with normal and thrombasthenic platelets on exposure to ADP or chymotripsin. Blood. 54:987-993.

37. Kornecki, E., S. Niewiarowski, T. A. Morinelli, and M. Kloczewiak. 1981. Effect of chymotripsin and adenosine diphosphate on the exposure of fibrinogen receptors on normal human and Glanzmann's thrombasthenic platelets. J. Biol. Chem. 256:5696-5701.

38. McEver, R. P., E. M. Bennet, and M. M. Martin. 1983. Identification of two structurally and functionally distinct sites on human platelet membrane glycoprotein IIb-IIIa using monoclonal antibodies. J. Biol. Chem. 258:5269-5275.

39. Bennet, J. S., J. A. Hoxie, S. F. Leitman, G. Vilaire, and D. B. Cines. 1983. Inhibition of fibrinogen binding to stimulated human plate- lets by a monoclonal antibody. Proc. Natl. Acad. Sci. USA. 80:24172421

40. Pidard, D., R. R. Montgomery, J. S. Bennet, and T. J. Kunicki. 1983. Interaction of AP-2, a monoclonal antibody specific for the human glycoprotein IIb-IIIa complex, with intact platelets. J. Biol. Chem. 258: 12582-12586.

41. McEver, R. P., N. L. Baenzinger, and P. W. Majerus. 1980. Isolation and quantitation of the platelet membrane glycoprotein deficient in thrombasthenia using a monoclonal hybridoma antibody. J. Clin. Invest. 66:1311-1318.

42. Nachman, R. L., and L. L. Leung. 1982. Complex formation of platelet membrane glycoproteins IIb and IIIa with fibrinogen. J. Clin. Invest. 69:263-269.

43. Hughes, J., J. P. Caen, R. M. Hardisty, and J. R. O'Brien. 1971. Discussion in round-the-table conference on normal and modified platelet aggregation. Acta Med. Scand. 525(Suppl.):204-205.

44. Cronberg, S. 1971. Abnormal behavior of platelets. In Platelet aggregation. J. P. Caen, editor. Masson et Cie, Paris. 185-191.

45. Caen, J. P., S. Cronberg, S. Levy-Toledano, P. Kubisz, and J. P. Pinkhas. 1971. New data on Glanzmann's thrombasthenia. Proc. Soc. Exp. Biol. Med. 136:1082-1086.

46. Chediak, J., M. C. Telfer, B. Vander Laan, B. Maxey, and I. Cohen. 1979. Cycles of agglutination: disagglutination induced by ristocetin in thrombasthenic platelets. Br. J. Haematol. 43:113-126.

47. Shattil, S. J., and J. S. Bennet. 1981. Platelets and their membranes in hemostasis: physiology and pathophysiology. Ann. Intern. Med. 94: $108-118$.

48. Kunicki, T. S., D. Pidard, J. P. Rosa, and A. T. Nurden. 1981. The formation of Ca-dependent complexes of platelet membrane glycoproteins IIb and IIIa in solution as determined by crossed immunoelectrophoresis. Blood. 58:268-278.

49. Jennings, L. K., and D. R. Phillips. 1982. Purification of glycoproteins IIb and IIIa from human platelet plasma membranes and characterization of a calcium-dependent glycoprotein IIb-IIIa complex. $J$. Biol. Chem. 257:10458-10466. 